\title{
Staff grade psychiatrists - a view from the inside
}

\author{
Aileen Blower and Diane Lusman
}

\begin{abstract}
With the recent establishment by the College of 'Affiliate' status for non-member psychlatrists and continuing professional development (CPD) for 'nontraining' grades, we though it timely to open a debate on the role, status and needs of staff grade doctors in psychiatry. Many of the lssues that need to be addressed are common to staff doctors in all speciallities. Following a brief description of the grade and how it is being used at present we will focus on education needs and career progression, drawing on recent debate in the medical liferature and our own experience as staff grade psychiatrists in the West of Scolland.
\end{abstract}

\section{The development of the grade}

The staff grade was introduced in 1988 following recognition that the limits on the numbers of doctors in training grades would leave a shortfall of doctors providing clinical services (Department of Health and Social Security, 1986). It was expected that doctors would enter the staff grade from senior house officer level, and that it should provide a secure career for doctors who are 'unable' or 'unwilling' to become a consultant. Entrants to the grade require a minimum of three years' full-time hospital service in the SHO or higher grade, and are expected to hold an 'intermediate' level of responsibility. Numbers in the grade are restricted to $10 \%$ of total consultant numbers. Two recent reports, from the Standing Committee on Postgraduate Medical Education (covering England and Wales) (SCOPME, 1994) and the Scottish Council for Postgraduate Medical and Dental Education (SCPMDE, 1996) show that most staff doctors do not fit this profile.

Who are the staff grades?

The SCOPME and SCPMDE reports collected demographic data referring to staff grade doctors in all specialities. Psychiatrists represent $10 \%$ of those surveyed. In terms of gender, it was shown that in Scotland $45 \%$ of staff grades were male, contrasting with $70 \%$ in England. Most male staff grades were born and qualified overseas, while most females were UK born and qualified. The average age of staff doctors is $\mathbf{4 0}$ years. Around $56 \%$ possess at least one full membership or fellowship of a Royal College. Almost half moved to the grade from a registrar post, and only 10 $14 \%$ from SHO level.

Why do doctors choose a staff grade post? The SCPMDE report offers four main reasons, listed in Table 1. Domestic and family commitments were important for men as well as for women.

\section{Our local experience}

There has been a rapid expansion of staff grade posts in psychiatry in the West of Scotland. Currently there are around 25 filled posts and several unfilled positions. Many of the posts in Glasgow are in Adult Community Mental Health Teams. Others include a variety of hospital based posts, such as acute in-patient care and day hospitals. Most postholders are UK born and qualified females with domestic commitments.

Following informal meetings in 1994, we formed the West of Scotland Staff Grade Psychiatrists' Committee. This group offers peer support and promotes the career and educational interests of its members. Discussions have highlighted many shared concerns. We have also been able to organise some successful clinical meetings. Two issues that frequently arise as major concerns for staff grades are career progression and education.

\section{Career progression}

The staff grade is a non-consultant career grade, envisaged as a career for those unwilling or unable to become consultants. The SCPMDE report shows that $21 \%$ of staff grades continue to

Table 1. Reasons for choosing a staff grade post

\begin{tabular}{ll}
\hline & \% \\
\hline Domestic and family commitments & 30 \\
Stability/permanence of post & 27 \\
Training or educational value & 20 \\
Inability to obtain SR/consultant post & 19 \\
Other & 4 \\
\hline
\end{tabular}


hope for a consultant post, and many others aspire to associate specialist. Within psychiatry at present this is certainly still possible, although it may become more difficult with increased competition for specialist registrar posts. In our locality we know of at least five staff grade psychiatrists who have progressed to senior registrar posts within the last 18 months, and who have been regraded to associate specialist.

\section{Present problems}

One major difficulty for those hoping to progress may be the present linear career structure which makes little or no allowance for a career break. This may well be ideal for many trainees who wish to complete their training as soon as possible, and there is immense pressure (often self-imposed) to keep up with peers and to complete examinations. 'Flexible' training has become more widely available recently, but in practice this is equivalent to part-time work on the same career ladder, taking twice as long to climb! Being resident 'on call' remains inextricably linked to training. For women, the period of the most arduous physical and academic work coincides with the childbearing years, leading to the difficult choice of postponing childbirth.

Another problem is the possible negative perception of staff doctors as being 'unable' or 'unwilling' to become a consultant. Such a description might well reflect a lifelong attitude to one's career, but could equally describe one's position at a particular stage or time of life. Most people's lifestyle, commitments and aspirations change over time. It might be interesting to review the career aspirations of staff doctors after 5-10 years in post. An ideal career structure would balance personal and professional development. The staff grade can allow 'space' for maturation and increasing confidence, essential for working with the greater responsibilities of a consultant.

\section{Positive career aspects}

Perhaps the most interesting and possibly unexpected reason for choosing a staff grade post was for its intrinsic educational or training value. We have personally found that there are many advantages in spending a relatively prolonged period in a single psychiatric post, a situation not usually experienced until consultant level. Examples include opportunities for longer-term audit and research, psychotherapeutic work, and experience in the management of persistent and relapsing illness. Continuity also facilitates development of working relationships with other professionals and agencies, and allows involvement in the development and expansion of services.
Present career options and future possibilities The staff grade should not be seen as an alternative training ladder. Many doctors will be happy to continue in a post which offers many of the advantages outlined above. Indeed, if employers wish to attract and keep 'good quality' staff doctors it is essential they provide a stimulating working environment with opportunities to develop each doctor's own potential and that of the service. Others may seek to re-enter specialist training at an appropriate level, or seek regrading to associate specialist.

With regard to the future, there has been some discussion about a parallel career structure, including all the non-consultant career grades, with a fair system of assessment and rewards for excellence (Davies, 1996). The Royal College of Physicians set up a working party to address some of the current problems of staff doctors (Royal College of Physicians, 1993). They suggested awarding "Proficiency Bars" determined by a combination of continuing medical education (CME) credits and interview. Passing these would permit upgrading of responsibilities. Promotion to associate specialist might be the final goal.

Moving back into the training grades at an appropriate level would require a more truly flexible career structure than is currently possible in many specialities, and a change in the perception of staff grade posts as 'jobs for life'.

\section{Education}

Education and training concern all staff grades, and are closely linked with career progression. However, the specific needs of each individual will depend on the level of previous training and ultimate career goal.

\section{Continuing Professional Development}

The College has recognised the importance of education in the response of several College committees and the Court of Electors to a memorandum on the subject (Royal College of Psychiatrists, 1989). This response was very positive, recognising the right to $\mathrm{CME}$ (now termed CPD) and protected study leave, both for the clinical duties of the post, and for the MRCPsych for individual doctors. The Royal College of Physicians' Working Party (1993) recommended that $\mathrm{CME}$ be developed along the lines of that for consultants, along with adequate time for audit and "other educational activities". They also recommended annual review of progress to include examination of the quantity of study leave taken. An interesting and innovative suggestion was that staff doctors might work in 
more than one specialist field over a period of time, adding interest and increasing experience.

CPD is of course as important for staff doctors as it is for consultants. If staff doctors and other affiliates are to feel included as psychiatrists in their own right it is extremely important that their need for CPD is taken seriously and we hope that this will be one of the priorities of the new Affiliates Group. A small group not to be overlooked are those staff doctors who are already College Members. At present these number around 60. Their needs will include recent advances and developments in their specialist fields, new drugs, and consolidation of a sound knowledge base. The needs of staff doctors who are not members will be similar but may include more basic further training needs and in some cases preparation for the MRCPsych.

\section{Progressing to College membership}

With regard to the MRCPsych our local experience reflects that elsewhere, with all staff grades possessing Part I at least. In general the College has been supportive of our peers' applications to sit membership examinations. The onus appears to lie with each individual to ensure that their post offers sufficient experience, supervision, and academic teaching to qualify for College approval for training purposes. Support from tutors in local approved training schemes is essential.

\section{Conclusion}

Intended as a solution to the manpower crisis within medicine, the staff grade has attracted psychiatrists with varying levels of experience and for many different reasons. It is not a substitute for good quality specialist training.
There is a great need for careful monitoring of staff grade posts and for further debate on the issue of career progression.

We have found that this intermediate career grade can offer clinical experience not found within the usual 'fast-track' route to a consultant post. There is a lot to be gained from an imaginative look at what this sizeable minority of career psychiatrists can offer our profession and our patients.

\section{Acknowledgement}

We would like to thank Dr $\mathrm{H}$. Livingston for helpful comments on the manuscript.

\section{References}

DAvies, R. (1996) Career progression is our number one priority (letter). British Medical Association. News Review, January 1996.

DEPARTMENT OF HEAlTH AND SOCLAl SECURTTY (1986) Hospital Medical Staffing: Achileving a Balance. London: DHSS.

RoYal College OF Physiclans of LoNDON (1993) Staff Grade Doctors-Towards a Better Future. Report of a Working Party. London: Royal College of Physiclans.

ROYAL COLLEGE OF PSYCHIATRISTS (1989) Education of the staff grade. Psychiatric Bulletin, 13, 581-582.

SCOTTISH COUNCIL FOR POSTGRAdUATE MEdical and DENTAL EDUCATION (1996) The educational needs of staff grade doctors and dentists in Scotland. Health Bulletin, 54 318-331.

Standing Committee on Postgraduate Medical Education (1994) Meeting the Educational Needs of Staff Grade Doctors and Dentists. London: SCOPME.

*Aileen Blower, Staff Grade Psychiatrist, Hartfield Clinic, Latta Street, Dunbarton G82 2DD; and Diane Lusman, Senior Registrar, Glasgow

*Correspondence 